\title{
Performance, teatralidad y espectáculo: el problema de nombrar las cosas.
}

M.H. José de Jesús Manuel Vargas

Escobedo

Universidad de Sonora

vargasj@voila.fr

\section{Introducción.}

Pasar del metarrelato al microrrelato, de la totalidad a la parcialidad es el rasgo más amplio y distintivo en el pensamiento posmoderno; no es extraño que la visión fragmentada de la realidad, inevitable en este paradigma, se manifieste en la creación artística y, de manera particular, en su expresión más polémica: la "performance".

La performance con pretensiones artísticas (o anti-artísticas) surge como variante del arte conceptual, donde la formalización y la técnica pasan a segundo término; la idea prima por encima de la materialización de la obra u objeto artístico; en este sentido, el proceso es lo más valioso, se opera sobre la realidad y, en consecuencia, la realidad es el espacio de intervención y el objeto mismo.

La palabra "performance", al ser un neologismo o una importación en la lengua castellana, ha sido empleada, en este idioma, de manera indiscriminada para designar diversos fenómenos dentro y fuera del terreno de las artes; me interesa, en este trabajo, contrastarla con los conceptos teatralidad y espectáculo con los que muchas veces se establece sinonimia, cuando en realidad son distintos y complementarios. Caracterizar la performance en el terreno del arte, considero, es fundamental para desambiguar su sentido y aplicación a un fenómeno que se genera con propósitos artísticos.

\section{El significado}

La palabra performance no está incluida en el Diccionario de la Real Academia de la Lengua Española, es una de las razones por la que algunos la rechazan, al considerar que su empleo tiene implicaciones colonizantes; es un término anglosajón que se traduce como "desempeño", "actuación"; Víctor Turner, citado por Diana Taylor, propone su comprensión a partir de aceptar que etimológicamente, la palabra parece provenir del verbo francés parfournir "proveer", "completar", "llevar a cabo por completo" (Taylor, 1999). En ambos casos, queda claro que no se refiere a las artes plásticas ni al teatro, al menos no de manera exclusiva: lo mismo se aplica al rendimiento del motor de un automóvil, que al comportamiento financiero de una empresa; a una modalidad de protesta política, que a una mujer realizando movimientos lúbricos al ritmo con que se golpea una caja de madera en un jardín público; a un espectáculo de luz y sonido en alguna pirámide mesoamericana, que al grupo de jóvenes circulando alrededor de un kiosco, cualquier domingo en algún pueblo michoacano; a un hombre que se encierra por días en una jaula con televisor, wáter y alimento chatarra, que a una mujer que marca con tinta roja su cuerpo mientras queda tendida sobre la plancha de una morgue; a una representación convencional de teatro o danza que a aquella manifestación frente al Palacio de Bellas Artes para oponerse a las corridas de toros.

Tal gama de significados hace parecer, a primera vista, inútil la palabra, más si se pretende tomar como concepto que ilu- 
mine una trayectoria metodológica de un proceso creativo.

Prieto (2009), establece el panorama de la falta de acuerdo, en el uso convencional de los términos performance y teatralidad que va desde la banalización de ambos por sinonimia, hasta su aplicación en la comprensión de los actos en cualquier dimensión de la vida social, donde siempre adquiere connotaciones políticas y/o rituales; también apunta el intento de delimitación de sus alcances en una sola dimensión: el arte.

En este terreno, el del arte, Martha Toriz entiende la performance como un movimiento propio del siglo XX, anclado en las vanguardias históricas y caracterizado por la necesidad urgente de diálogo entre las diversas disciplinas artísticas, fragmentadas históricamente desde la antiguiedad clásica grecolatina (Toriz, 1997). Diana Taylor, por su parte, defiende la au- tonomía y valor del término "performance", frente a "teatralidad" y "espectáculo", términos con que en Latinoamérica suele sustituírsele:

Teatralidad, desde mi punto de vista, implica un escenario, una puesta en escena paradigmática que cuenta con participantes supuestamente "en vivo", estructurada alrededor de un guión esquemático, con un "fin" preestablecido (aunque adaptable)... La teatralidad (como el teatro) hace alarde de su artificio... Connota una dimensión consciente, controlada y, de esa manera, siempre política, que "performance" no necesariamente implica. Difiere de 'espectáculo' en que la teatralidad subraya la mecánica del espectáculo...Mucho se pierde, a mi entender, cuando resignamos el potencial para la intervención directa y activa al adoptar términos como "teatralidad" o "espectáculo" para reemplazar a "performance" (Taylor, 1999).

Taylor explica cómo en los países anglosajones "performance" adquiere un sentido ontológico pues incluye los saberes, la memoria y la identidad transmitidos mediante prácticas reiteradas en la vida social y que éstas implican comportamientos teatrales, por lo tanto, performance implica un fenómeno simultáneamente "real" y "construido". Así, el concepto parece funcionar más en el terreno antropológico que estudia las manifestaciones culturales a partir de las prácticas cotidianas: "performances".

Resulta significativo que la investigadora Roselee Goldberg, haya añadido la palabra "arte" a continuación de la palabra "performance" como un intento de focalización, en el título de su libro. Implícitamente es un reconocimiento de la gran 
extensión semántica de "performance" y de la necesidad de delimitar los campos de su aplicación. Aun así, en el mismo libro se reconoce la complejidad para establecer una definición, en este caso, de aquella producción artística que cubre ciertas características y que llamamos performance:

(...) Por su propia naturaleza, la performance escapa a una definición exacta o sencilla más allá de la simple declaración de que es arte vivo hecho por artistas. Cualquier definición más estricta negaría de manera inmediata la posibilidad de la propia performance. Puesto que recurre libremente a cualquier número de disciplinas y medios de comunicación (literatura, poesía, teatro, música, danza, arquitectura y pintura, además de video, film, diapositiva y narración) en busca de material, los despliega en cualquier combinación, cada intérprete hace su definición particular en el proceso y la manera propios de la ejecución (Goldberg, 1996, p. 9).

Por su parte, Alfonso de Toro, al caracterizar al teatro posmoderno, ofrece claves para la definición de la performance:

Se trata de un teatro (el posmoderno) en el cual se celebra el arte como ficción y el teatro como proceso, 'performance', no-textualidad (ejemplos: Living Theatre, Happening, teatro antropológico, ritual, mítico, etc.), donde el actor se transforma en el tema y personaje principal, y el texto es, en el mejor de los casos, sólo una base que -generalmente- carece de importancia. El texto es considerado como una forma autoritaria y arcaica y pasa a ser un performan- ce script. La idea de performance toma una tercera posición -mediadora y subversiva- entre drama y teatro". (Toro, 2004).

De manera más radical, podría decirse que es el cuerpo, y no el actor, el tema y personaje principal de la performance, operando éste como el espacio simbólico de la experiencia humana. De Toro escribió en otro texto: "el cuerpo como un proscenio teatral en el cual se inscriben y se leen procesos culturales, produciendo al mismo tiempo significación y diseminación" (2001).

\section{Performance vs. Teatralidad.}

El mismo De Toro desarrolla una reflexión sobre el término "teatralidad", que nos permite ganar precisión para su empleo.

El concepto puede entenderse como un lugar operativo en la construcción de relaciones transversales y entrelazamientos de diversas formas de representación, una operación transrelacional en el intercambio de comunicación... El término describe el empleo de una enorme e infinita posibilidad de procesos dinámicos de representación. La 'teatralidad' así descrita no puede entenderse como una categoría semántica (que se ocupa del contenido del acto de representación), sino como relación de diversas y simultáneas formas de representación, es decir, una categoría al nivel del significante (Toro, 2001).

Este planteamiento resulta práctico, porque nos permite comprender la teatralidad como el plano de la expresión de toda performance $-\mathrm{y}$, por supuesto, de toda producción teatral- como la selección de 
los recursos escénicos que serán vehículo de los contenidos. La teatralidad como el juego de artificios formales que harán más eficiente y más atractivo el proceso de comunicación.

\section{Performance vs. Espectáculo}

Otro problema por resolver es el sentido de la palabra espectáculo y su relación con la performance. El diccionario de la RAE ofrece cuatro acepciones para el significado del término, de las cuales tres son pertinentes para este trabajo: como función o diversión pública; como el conjunto de actividades profesionales para realizarla; y como la cosa misma que se ofrece a otros, en forma atractiva, para provocar deleite, dolor, asombro, etc.

Un evento, una técnica y modos (códigos) de presentación, son los tres elementos que se pueden inferir de la definición. La intencionalidad de que el evento, hecho u objeto presentado resulte "atractivo" para un público será lo determinante en la definición de materiales y selección de recursos que darán como resultado la materialización del espectáculo. De Toro opina que la espectacularidad -es decir el adjetivo, el atributo- es definitoria del paradigma del teatro actual: “... esto es, del uso de una gran cantidad de códigos que se entienden como materia visual-sonora-gestualkinésica..." (2004).

De manera que, al hablar de espectáculo y de espectacularidad, nos remitimos, de alguna manera, a los ideales wagnerianos del arte total, el teatro como integrador de los lenguajes de todas las artes; o nos hace recordar las seratas futuristas, evocar a Gropius en el manifiesto de la Bauhaus en que visualizó la urbanización del futuro con la integración de arquitectura, pintura y escultura; y, por supuesto, nos instala en la pirotecnia vanguardista para llamar la atención mediante la multimedialidad.

\section{Performance y simulación.}

Eduardo Subirats, controvertido filósofo catalán y observador de la cultura contemporánea, propone los postulados de las vanguardias históricas como puntos de anclaje de la cultura tardo y posmoderna, en el sentido de que estos son el sustento de un proyecto estético y civilizatorio que pretende crear una "segunda naturaleza y producción de simulacros" (1997, pág. 14) que se manifiesta plenamente en la cultura mediática contemporánea, con la creación de una segunda realidad, a la vez electrónica y espectacular.

Efectivamente, la performance tiene su anclaje en las vanguardias artísticas del siglo XX, es un modelo de expresión humana que cumple con los postulados vanguardistas, desde que los pintores futuristas deciden poner al espectador en el centro de la acción, y Duchamp estampa su firma en un urinal para presentarlo como obra artística, sin embargo la performance, como arte de acción, lleva el simulacro hasta sus últimas consecuencias, rompe con la ficcionalidad, la representación y la referencialidad, ofreciendo simulacros que se viven como realidades alternas o realidades virtuales.

Jean Baudrillard (1978, pp. 7, 8) aporta a la comprensión del mecanismo fundamental en la generación de performances, al explicar la simulación como "suplantación de lo real por los signos de lo real", consecuencia de ello es que la performance es un evento a la vez real y construido pues, añade el autor "la simulación vuelve a cuestionar la diferencia de lo «verdadero»y de lo «falso», de lo «real»y de lo «imaginario»"; la performance nos ofrece acontecimientos (simulacros) que ocurren frente a nuestros ojos como realidades, no como representaciones. 


\section{Performance en latino-améri- ca (muestras)}

En el año 2008, se efectuó PerfoArtNet Encuentro Internacional de Artistas del Performance, con transmisiones en directo por Internet. Este evento incluyó la presentación de discusiones teóricas, talleres, grupos de trabajo, etc. Este encuentro contó con la asistencia de performanceros de Canadá, México, Venezuela, Chile, Argentina, Islas Canarias, España, Portugal, Estados Unidos y Colombia. Fernando Pertuz, performer y artista colombiano participante de este encuentro, escribe:

Performance o Arte de Acción es el nombre usado para denominar a una técnica que cumplirá 100 años con estos calificativos... Pero que está desde los comienzos de la civilización humana en las relaciones arte, cuerpo, vida y pensamiento... La utilización del cuerpo por artistas plásticos, pintores, escultores, músicos, filósofos, pensadores y creadores como acción o performance aparece en los libros desde 1909 con las muestras realizadas por los Futuristas, los constructivistas, los surrealistas, los dadaístas y Fluxus" (Pertuz, 2008).

La pertinencia de esta cita se justifica por dos razones: la primera, por el reconocimiento convencional de la palabra "performance", por gran parte de los practicantes iberoamericanos, de esta modalidad artística y, segundo, porque, de manera explícita, reconocen su origen en las vanguardias históricas del siglo XX. Lo mismo ocurre, desde su nombre mismo, con la publicación venezolana Performanceología (2006) que, desde sus páginas "on line", se ha convertido en un foro latinoamericano de discusión, historia, información, intercambio de experiencias y documentación sobre arte de performance y performancistas.
En México, el Centro Nacional de Investigación y Documentación Teatral "Rodolfo Usigli" mantiene una línea de investigación sobre performance, fenómeno al que dedicó en forma íntegra, el primer número de la publicación Citru. doc (2005); en este cuaderno pueden encontrarse afirmaciones tan radicales como que la performance "no tiene que ver con el teatro..." o "Debe estar desierta de cualquier valor estético" y no ser interpretable o, como afirma Gurrola en una entrevista publicada en el mismo cuaderno, que la performance "sólo se les aparece a los iluminados"; también se encuentran en el otro extremo, posturas flexibles, como es el caso de Josefina Alcázar quien, aun cuando considera "que estas teatralidades ponen en crisis la idea misma del teatro, como también desestabilizan los mecanismos tradicionales de la crítica", acepta mecanismos en la creación de la performance, más acá de la "iluminación", como hibridación y transversalidad.

\section{Consideraciones finales}

Fuera del discurso académico, existe entre los "performers" el rechazo a ser considerados actores, pues niegan ser ejecutantes de una "representación" a la que oponen la idea de "presentación". Tiene sentido el rechazo cuando históricamente fueron las artes plásticas quienes generan un registro nuevo, al trasladar el contenido del lienzo y la escultura al cuerpo humano en acción. Presentar en una performance significa generar acciones que acontecen en un "presente", que carece de referente en el pasado, por lo que adquiere un sentido autorreferencial, otro rasgo distintivo de las expresiones posmodernas.

Si bien ha de reconocerse el origen de la performance en las expresiones vanguardistas de las artes plásticas, nadie puede negar el abordaje de esa nave desde la música y las artes escénicas. La performance dejó de ser una manifestación ex- 
clusiva de la plástica y ahora su sello es la diversidad.

Sin embargo, considero que la libertad creativa, la independencia de las normas estéticas y de la sintaxis propia de lenguajes específicos, no son razones para obviar el hecho de que toda performance es un diseño derivado de una idea; un concepto que se materializa plásticamente y esto, la propuesta plástica, es lo que mantiene anclada la performance con sus orígenes y le otorga valor estético.

Con lo expuesto hasta aquí y a partir de la observación directa como espectador o indirecta mediante videograbaciones, presento a continuación una síntesis personal, de lo que llamamos performance. Aclaro que para establecer el bosquejo de una caracterización, opté por los criterios que focalizan la dimensión artística del fenómeno.

Primero, considero que no hay oposición entre los términos, performance, teatralidad y espectáculo, tampoco hay sinonimia. Cada uno de ellos aporta contenidos semánticos diferenciados presentes en cualquier performance art.

Segundo, el término performance cobra autonomía y valor conceptual, cuando se le asocia a un cierto tipo de productos artísticos, caracterizados por:

a) Distanciarse de las normas académicas y estéticas predominantes, en cualquier terreno de las artes, en un momento determinado.

b) No ser susceptibles de clasificación taxonómica (género, estilo, etc.).

c) Ser autorreferenciales. El ejecutante suele exponer parte de su propia existencia y estructura emocional o del contexto temporal y social en que se desenvuelve.

d) Carecer de estructura dramática, más no de teatralidad.

e) No estar confinada a espacios convencionales o predeterminados, cualquier sitio puede ser el lugar de la ejecución.

f) Que el ejecutante tiene un propósito deliberado de comunicación sin que la narración-representación sea su principal estrategia. g) Presentarse como un híbrido de artes escénicas, plásticas, audio-visuales y literatura.

h) La libertad de creación sin más frontera que la determinada por los propios ejecutantes.

i) Y por la ejecución, en presente, de acciones que simulan eventos en la realidad. Reconozco, como lo han hecho otros investigadores, además de apuntar algunos rasgos más o menos comunes de la performance, la imposibilidad de generar una definición general para abarcar el fenómeno; tratar de lograrlo implicaría contradecir la lógica posmoderna.

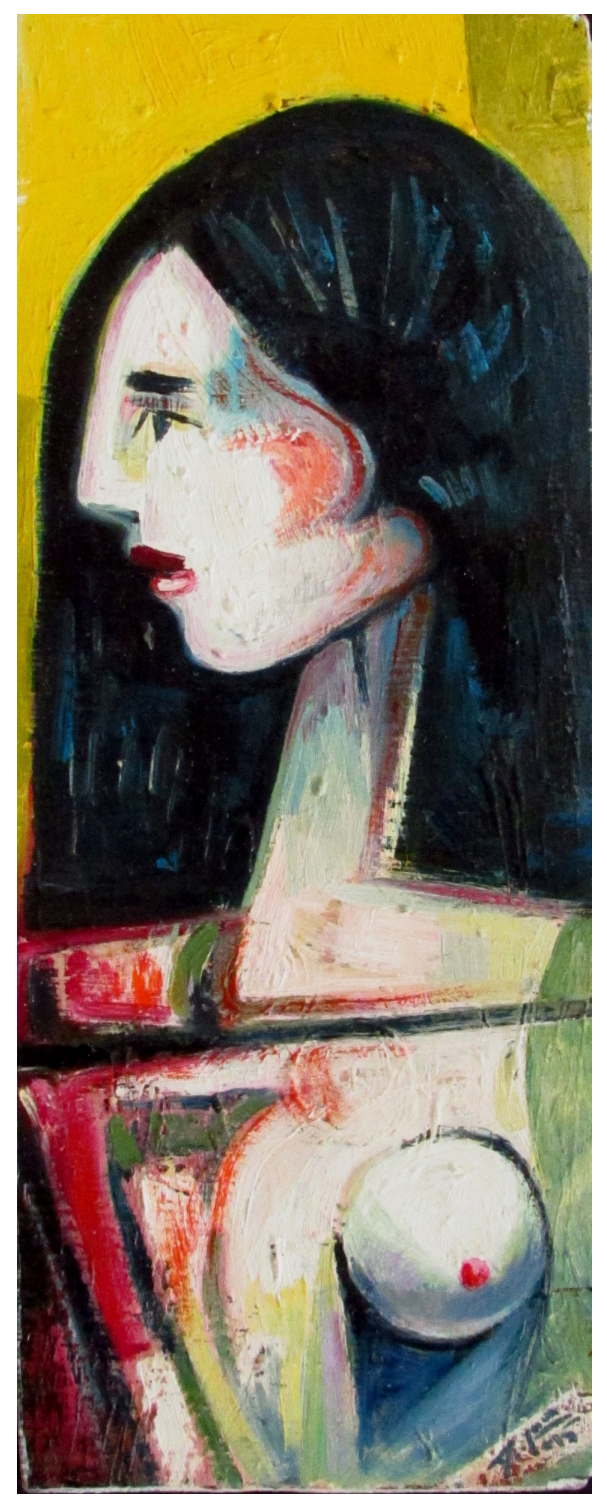

David Ozuna. Perfiles 
Lo que sí se puede plantear es que, a diferencia de Duchamp en los albores del siglo XX, el performer del presente siglo no se conforma con devolver a la realidad un objeto modificado y resignificado fuera de su contexto original, sino un acontecimiento, una nueva realidad, así sea virtual o simulada. Simulacro y propuesta plástica - el mecanismo y el diseño para apelar a los sentidos del es- pectador- son quizá las únicas condiciones exigibles a esta modalidad del arte. Ejecución en presente, siempre irrepetible, donde el proceso es más valioso que cualquier objeto o imagen que pudiera gestarse en el camino. Bajo estas premisas, el arte de acción es, entonces, la ejecución misma y legitima su nombre: performance.

Bibliografía

Baudrillard, J. (1978). Cultura y simulacro. Barcelona: Kairós.

Centro de Investigación Teatral "Rodolfo Usigli" INBA. (2005). Citru.doc No.1 (cuadernos de investigación teatral). México: INBA.

Goldberg, R.-L. (1996). Performance art. Barcelona: Ediciones Destino.

(2003). Arte de acción y participación: Happening, Fluxus. En A. Guasch Ferrer, Historia Universal del Arte, v, 11: Arte del siglo XX.De la Segunda Guerra Mundial a nuestros días. Madrid: Espasa Calpe.

Performanceología. (2006). Recuperado el 10 de diciembre de 2012, de Performanceología. Todo sobre el Arte del Performance y Performancistas: http://performanceologia. blogspot.com

Pertuz, F. (21 de Mayo de 2008). Radio y tv Indymedia Colombia. Recuperado el 20 de Marzo de 2010, de PerfoArtNet Encuentro Internacional de Artistas del Performance: http://colombia.indymedia.org/news/2008/05/87058.php

Prieto, A. (2009). i Lucha libre! Actuaciones de teatralidad y performance. Actualidad de las artes escénicas. Perspectiva latinoamericana, 116-143.

Subirats, E. (1997). Linterna Mágica (Vanguardia, media y cultura tardomoderna). Madrid: Ediciones Siruela.

Taylor, D. (Junio de 1999). CRIM-UNAM/Memorias del Coloquio Diversidad Cultura y Creatividad. Recuperado el 17 de Diciembre de 2009, de Hacia una definición de Performance: http://132.248.35.1/cultura/ponencias/PONPERFORMANCE/Taylor.html

Toriz, M. (1997). Discursos del Arte: el Teatro y el Performance. En S. E. Véjar, La otredad (Los discursos de la cultura hoy:1995) (págs. 153-162). México: Universidad Autónoma Metropolitana Azcapotzalco, Centro de Cultura Casa Lamm, Universidad de Louisville, Kentucky.

Toro, A. d. (2001). Publikationen von Prof. Dr. Alfonso de Toro. Recuperado el 10 de Enero de 2010, de Reflexiones sobre fundamentos de investigación Transdisciplinaria, Transcultural y Transtextual en las Ciencias del Teatro: http://www.uni-leipzig.de/ detoro/sonstiges/Reflexiones.htm

Toro, A. d. (2004). Publikationen von Prof. Dr. Alfonso de Toro. Recuperado el 16 de Enero de 2010, de Los Caminos del Teatro Actual: Hacia la plurimedialidad Espectacular Posmoderna o ¿El fin del Teatro Mimético Referencial?: http://www.uni-leipzig. de/ detoro/sonstiges/Caminos.pdf 